\title{
CAFEÍNA: REVISÃO SOBRE MÉTODOS DE ANÁLISE
}

\section{Carlos A. B. De Maria* e Ricardo F. A. Moreira}

Departamento de Ciências Fisiológicas, Instituto Biomédico, Universidade Federal do Estado do Rio de Janeiro, Rua Frei Caneca, 94, 20211-040 Rio de Janeiro - RJ, Brasil

Recebido em 19/8/05; aceito em 24/3/06; publicado na web em 30/8/06

\begin{abstract}
ANALYTICAL METHODS FOR CAFFEINE. Gravimetric and Bailey-Andrew methods are tedious and provide inflated results. Spectrofotometry is adequate for caffeine analysis but is lengthy. Gas chromatography also is applied to the caffeine analysis but derivatization is needed. High performance liquid chromatography with ultraviolet detection (HPLC-UV) and reversed phase is simple and rapid for xanthine multianalysis. In HPLC-UV-gel permeation, organic solvents are not used. HPLC-mass spectrometry provides an unequivocal structural identification of xanthines. Capillary electrophoresis is fast and the solvent consumption is smaller than in HPLC. Chemometric methods offer an effective means for chemical data handling in multivariate analysis. Infrared spectroscopy alone or associated with chemometries could predict the caffeine content in a very accurate form. Electroanalytical methods are considered of low cost and easy application in caffeine analysis.
\end{abstract}

Keywords: caffeine; methylxanthines; analytical methods.

\section{INTRODUÇÃO}

A cafeína é um alcalóide, identificado como 1,3,7-trimetilxantina, cuja estrutura contém um esqueleto de purina (Figura 1). Este alcalóide é encontrado em grande quantidade nas sementes de café (Coffee $\mathrm{sp}.)^{1}$ e nas folhas de chá verde (Camilla sinensis) ${ }^{2}$. Também pode ser achado em outros produtos vegetais, particularmente no cacau (Theobroma cocoa) $)^{3}$, no guaraná (Paullinia cupana) e na erva-mate (Ilex paraguayensis) ${ }^{2}$. Embora uma parcela pequena da população consuma cafeína na forma de fármacos, como por ex. antigripais, grande parte deste alcalóide é ingerida na forma de bebidas. Uma xícara de café pode conter em média cerca de $80 \mathrm{mg}$ de cafeína, enquanto uma lata de coca-cola em torno de 34-41 $\mathrm{mg}^{4}$.

A cafeína é um dos alcalóides com atividade biológica mais ingeridos no planeta. Apresenta ação farmacológica variada provocando, dentre outros efeitos, alterações no sistema nervoso central, sistema cardiovascular e homeostase de cálcio. Os efeitos da cafeína sobre o comportamento humano têm sido objeto de estudos a algumas décadas. Esses efeitos podem ser descritos como ${ }^{5-7}$ aumento da capacidade de alerta e redução da fadiga, com concomitante melhora no desempenho de atividades que requeiram maior vigilância. Em contrapartida, o consumo de cafeína pode afetar negativamente o controle motor e a qualidade do sono, bem como causar irritabilidade em indivíduos com quadro de ansiedade ${ }^{6}$. O efeito da ingestão de cafeína sobre o sistema cardiovascular ainda é motivo de grande controvérsia ${ }^{8,9}$. Seu consumo regular parece elevar a pressão arterial de forma persistente e, desta forma, indivíduos com hipertensão, doença coronariana e arritmia cardíaca deveriam ser encorajados a reduzir seus níveis de ingestão de cafeína ${ }^{10-12}$. Com relação à homeostase de cálcio, dados compilados em uma revisão indicam que a cafeína não é prejudicial ao metabolismo ósseo de indivíduos cujo consumo de cálcio é adequado as suas necessidades metabólicas ${ }^{13}$. Um estudo sobre os efeitos da cafeína na saúde humana indicou que seu consumo moderado (máximo de 4,6 mg/kg de peso), praticado por adultos saudáveis em idade reprodutiva, não está associado a efeitos adversos ${ }^{14}$.

*e-mail: carreb@uol.com.br

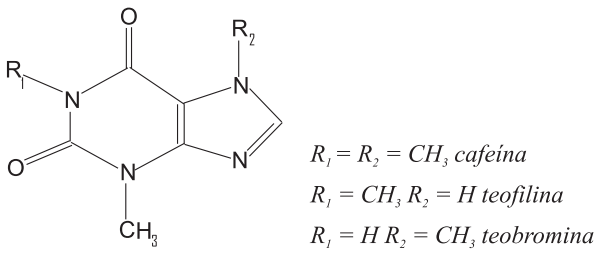

Figura 1. Estrutura química da cafeína e de outras metilxantinas

Em face do seu largo espectro de ação fisiológica, existe, de fato, um grande interesse da comunidade científica no estabelecimento de níveis seguros de ingestão de cafeína para diversos subgrupos populacionais humanos. Além disso, a cafeína é uma droga estimulante que pode ser usada indevidamente em atividades esportivas oficiais e, portanto, necessita ser monitorada continuamente durante as competições. Evidentemente o conhecimento das técnicas para análise de cafeína em matrizes alimentícias e fluidos biológicos, bem como suas vantagens e limitações, é um fator primordial para monitorar os níveis de cafeína no organismo. O objetivo deste trabalho é apresentar uma revisão crítica sobre os principais métodos descritos na literatura para análise de cafeína.

\section{MÉTODOS ANALÍTICOS}

\section{Gravimetria e determinação de nitrogênio}

A gravimetria foi o primeiro método desenvolvido para análise de cafeína em produtos alimentícios. Durante muitos anos foi o método oficial da "Association of Official Analytical Chemists" (AOAC) para análise de cafeína em semente de café ${ }^{15}$. A técnica consistia na extração do produto com água ou etanol, limpeza do filtrado com óxido de magnésio e extração subseqüente com clorofórmio. Após a evaporação do clorofórmio, o conteúdo de cafeína era determinado por gravimetria. Esse método consumia muito tempo e nem todos os interferentes eram removidos, o que causava uma superestimativa dos níveis de cafeína no produto. Em 1947, o método denominado "Bailey-Andrew", adotado pela AOAC somente para análise de cafeína em chá, passou a ser adotado oficialmente pela AOAC para análise de cafeína em produtos 
do café ${ }^{16}$. Neste método, as etapas de extração e limpeza foram otimizadas para redução do tempo de análise. A principal diferença entre este método e o gravimétrico era a determinação de nitrogênio total, no extrato clorofórmio, pelo aparato de "Kjeldahl" e a conversão do teor de nitrogênio para cafeína. Embora o método "Bailey-Andrew"16 consumisse menos tempo que o método gravimétrico ${ }^{15}$, apresentava uma limitação importante que era a contabilização de outros compostos nitrogenados, presentes no extrato clorofórmio, causando uma superestimativa nos valores de cafeína.

\section{Espectrofotometria}

A absorção de radiação eletromagnética na região do ultravioleta (UV) pela cafeína foi descrita no início do século 20 por Hartley ${ }^{17}$. Posteriormente, Holiday ${ }^{18}$ descreveu que a cafeína apresentou um limite máximo de absorção no UV entre os comprimentos de onda de 271 e $275 \mathrm{~nm}$. Ishler et al. ${ }^{19}$ desenvolveram um método espectrofotométrico de baixo custo para análise de cafeína em produtos do café. O extrato aquoso da matriz foi tratado com óxido de magnésio e ferrocianeto de zinco para remoção de trigonelina e outros compostos interferentes. A quantificação da cafeína foi conduzida com base na análise da absorvância no comprimento de onda de 272 $\mathrm{nm}$. Este método é mais rápido, simples e preciso que as técnicas gravimétricas ${ }^{15}$ e de análise do nitrogênio tota ${ }^{16}$, porém os resultados ainda podem ser superestimados pela presença de interferentes.

\section{Cromatografias de adsorção e camada delgada}

A partir da década de 60, foram publicados alguns artigos enfocando o uso da cromatografia líquida clássica para análise de cafeína em bebidas ${ }^{20-23}$. Este método permitiu uma limpeza mais eficiente dos extratos, o que propiciou análises mais exatas do teor de cafeína nas matrizes analisadas. Posteriormente, um trabalho colaborativo $^{24}$, envolvendo 9 laboratórios, comparou o método cromatográfico, com quantificação da cafeína pela análise da absorvância na região do UV, com o método "Bailey-Andrew" ${ }^{16}$. De modo geral, o estudo colaborativo indicou uma correlação satisfatória entre os 2 métodos, entretanto o método "Bailey-Andrew"16 apresentou resultados superestimados para o café descafeinado. O método cromatográfico-espectrofotométrico ${ }^{24}$ consistiu na passagem do extrato em uma coluna de celite básica. Em seguida, a cafeína juntamente com pigmentos foram dessorvidos com éter. O extrato etéreo então foi passado em uma coluna celite ácida, na qual somente a cafeína ficou adsorvida. Por último, a cafeína foi eluída da coluna com clorofórmio e quantificada pela análise da absorvância no comprimento de onda de $276 \mathrm{~nm}$. A partir da década de 80, o método cromatográfico-espectrofotométrico ${ }^{24}$ foi adotado oficialmente pela AOAC, em substituição ao método "Bailey-Andrew"16, para análise de cafeína em produtos do café.

A cromatografia em camada delgada também foi usada para detecção de cafeína em matrizes alimentícias ${ }^{25,26}$. Abourashed e Mos$\mathrm{sa}^{26}$ determinaram o conteúdo de cafeína em alguns chás e bebidas energéticas, através da cromatografia em camada delgada de alta eficiência, sobre placas de sílica gel, com análise densitométrica na região do UV. A fase móvel consistiu de acetato de etila e metanol (85:15, v/v) e a detecção foi conduzida no comprimento de onda de $275 \mathrm{~nm}$. O método foi testado quanto à repetibilidade, recuperação e exatidão, mostrando resultados satisfatórios.

\section{Cromatografia gasosa (CG)}

A partir da década de 70 , houve a necessidade de se desenvolver métodos que oferecessem maior reprodutibilidade e sensibilidade e pudessem ser aplicados para análise de cafeína em pequenos volumes de amostra. A CG foi um dos métodos testados para este propósito, sendo a detecção realizada com o auxílio de um detector de ionização de chama (DIC) e a separação conduzida, principalmente, em coluna de vidro recheada com $2 \%$ de polietilenoglicol ${ }^{27}$ ou $2,5 \%$ de SE-30 ${ }^{28}$. Segundo Strahl et $a l .^{28}$, a técnica de CG permitiu a determinação rápida, e com alta reprodutibilidade, de pequena quantidade de cafeína em um volume reduzido de amostras de chá e café. Recentemente, Thomas e Foster ${ }^{29}$ usaram CG acoplada à espectrometria de massas (EM) para analisar uma série de compostos, dentre eles a cafeína, em efluentes oriundos de uma unidade de tratamento de resíduos aquosos. Os compostos foram isolados em um sistema de extração em fase sólida e separados em coluna capilar de sílica fundida. O método apresentou ótima especificidade e sensibilidade, sendo possível determinar o conteúdo de cafeína na ordem de grandeza de $\mathrm{ng} \mathrm{L}^{-1}$.

\section{Cromatografia líquida de alta eficiência (CLAE)}

\section{$C L A E-U V$}

A CLAE foi usada na análise de cafeína, pela primeira vez, no ínício da década de 70. Inicialmente, Murgia et al. ${ }^{30}$ usaram cromatografia de troca iônica para separar a cafeína de outros compostos orgânicos em café. Esses autores empregaram uma resina de poliestireno sulfonado com $4 \%$ de ligações cruzadas, tendo como contra-íon o cátion amônio. O maior incoveniente foi a baixa estabilidade mecânica da resina à pressão de trabalho acima de $3 \mathrm{MPa}$, o que limitou a vazão da fase móvel. Com a introdução da coluna de fase reversa, houve um grande avanço na análise de compostos de baixa massa molar (MM) por CLAE. Este tipo de coluna consistiu de sílica, inicialmente com partículas de $40 \mu \mathrm{m}$, modificada pela ligação covalente com octadecilsilano, o qual conferiu apolaridade e maior estabilidade mecânica ao suporte. Mais tarde, o desenvolvimento de fases estacionárias, contendo micropartículas $(5 \mu \mathrm{m})$, permitiu melhor resolução e um menor tempo de análise, contribuindo para a maior difusão da CLAE. Desta forma, a cromatografia de fase reversa foi aplicada para análise de cafeína em diferentes matrizes alimentícias, como café ${ }^{31}$, chocolate ${ }^{32}$ e chá ${ }^{33}$. Em ambos os casos, os extratos contiveram uma grande carga de interferentes que dificultou a análise cromatográfica. Trugo et al. ${ }^{34}$ desenvolveram um método simples e rápido para a análise simultânea de trigonelina, cafeína e outras metilxantinas em cafés solúveis e outras bebidas. Esses autores usaram solução aquosa saturada de acetato de chumbo básico para clarificar as amostras. O precipitado foi removido por filtração simples, obtendo-se extratos bem mais límpidos que aqueles obtidos por tratamento com solvente orgânico. Uma outra inovação foi o emprego do sistema gradiente para separação da cafeína de outras metilxantinas. A fase móvel consistiu de metanol em solução aquosa de citrato de tri-potássio 0,015 mol L ${ }^{-1}, \mathrm{pH}=6$, na qual a concentração de metanol aumentou linearmente de 0 a $60 \%$ em 10 min. Essa inovação permitiu uma redução no tempo de análise sem comprometer a resolução dos analitos.

Muhtadi et al. ${ }^{35}$ compararam a CLAE de fase reversa com a CG para determinação de metilxantinas em diversos produtos alimentícios. Concluíram que a resolução da cafeína e de outras metilxantinas foi efetivamente superior com o uso da CLAE de fase reversa. Nakakuri et al. ${ }^{36}$ desenvolveram um método para remover compostos polifenólicos a fim de facilitar a análise de metilxantinas. A técnica foi baseada no uso de uma pré-coluna preenchida com polivinilpolipirrolidona pulverizada. Horie et al. ${ }^{37}$ concluíram que, de fato, a fração polifenólica interfere na determinação de cafeína, sendo importante o uso desta pré-coluna para sua remoção em folhas de chá com baixissímos teores de cafeína.

O emprego do sistema DAD (detector de arranjo de diodos), o 
qual permitiu a análise da absorvância em todos os comprimentos de onda da região do UV simultaneamente, aumentou a precisão e a exatidão na multianálise de compostos pela CLAE. Casal et al. ${ }^{38,39}$ usaram a cromatografia de fase reversa com DAD para análise simultânea de trigonelina, niacina e cafeína em amostras de café. As matrizes foram extraídas com água quente e os respectivos extratos foram filtrados em membranas com porosidade de $0,2 \mu \mathrm{m}$. A fase móvel, no modo gradiente, foi composta de metanol em solução aquosa de tampão fosfato $0,1 \mathrm{~mol} \mathrm{~L}^{-1}, \mathrm{pH}=4$.

A CLAE-UV é usada freqüentemente para análise de cafeína e seus metabólitos em fluidos biológicos. Esta abordagem é importante para o estabelecimento de níveis seguros de ingestão da cafeína, bem como para inibir seu uso indevido em modalidades esportivas. Ventura et al. ${ }^{40}$ monitoraram a estabilidade da cafeína em amostras de urina. A cafeína foi isolada por extração líquido-líquido em $\mathrm{pH}$ alcalino com sistema binário de solventes composto de clorofórmio e 2-propanol $(9: 1, \mathrm{v} / \mathrm{v})$. Tanto a urina estocada a $37{ }^{\circ} \mathrm{C}$ por 7 dias como também aquela estocada a $-20{ }^{\circ} \mathrm{C}$ por 18 meses não apresentaram perdas significativas de cafeína. Emara ${ }^{41}$ usou uma pré-coluna de sílica modificada com grupamento cianeto para limpeza de amostras de plasma. A cafeína e seus metabólitos foram dessorvidos da pré-coluna com a própria fase móvel do sistema cromatográfico composta de metanol e tampão fosfato $0,01 \mathrm{M}, \mathrm{pH}=5(30: 70, \mathrm{v} / \mathrm{v})$. Zydron et al. ${ }^{42}$ usaram uma coluna de extração em fase sólida de octadesilsilano, de composição idêntica à da coluna analítica, para isolar cafeína e teofilina da urina de pacientes com asma crônica ou saudáveis. Os compostos foram separados por cromatografia de fase reversa com fase móvel, modo gradiente, composta de solução aquosa de ácido trifluoracético $0,05 \%$ e acetonitrila. A CLAE-UV/DAD com coluna de fase reversa foi usada para multianálise de cafeína e seus metabólitos na urina ${ }^{43}$. A fase móvel consistiu de uma mistura de metanol e tampão (20:80, v/v). O tampão foi composto de ácido cítrico $5 \mathrm{mmol} \mathrm{L}^{-1}$ ajustado a $\mathrm{pH}=5$ com trietilamina. $\mathrm{O}$ método alcançou grande exatidão, já que cada composto foi analisado no comprimento de onda específico onde ocorreu o seu máximo de absorção.

\section{CLAE-UV e CLAE-IR (índice de refração) com coluna de permeação em gel}

$\mathrm{Na}$ década de 90, foram publicados alguns artigos científicos enfocando a multianálise de compostos de baixa MM, através da CLAE com coluna de permeação em gel do tipo TSK. O avanço na tecnologia de produção de fases estacionárias usadas em colunas de permeação em gel propiciou o desenvolvimento de fases mecanicamente estáveis às pressões exercidas na CLAE. Embora este tipo de coluna seja adequado para separar compostos com MM acima de 1000, foi possível separar compostos com MM em torno de 100700. A interação hidrofóbica seria o fenômeno físico responsável pela adsorção dos compostos de baixa MM, o que permitiu que a resolução entre eles fosse satisfatória.

Müller e Jork ${ }^{44}$ usaram a cromatografia de permeação em gel com coluna TSK HW-40 (S) para separar sacarina, aspartame e cafeína em bebidas não alcoólicas. Foi usado o modo isocrático com água como fase móvel, sendo obtida uma boa resolução dos compostos e repetibilidade satisfatória. Na mesma época, um grupo de pesquisadores do Brasil, trabalhando de maneira independente, publicou alguns artigos sobre o uso da coluna TSK G3000SW na análise simultânea de compostos de baixa MM em extratos aquosos de café1,45,46. O objetivo foi desenvolver um método multianalítico que pudesse ser automatizado para uso no controle de qualidade de produtos do café. Foi possível analisar cafeína, trigonelina, sacarose e ácido clorogênico total nesses produtos com precisão e exatidão adequadas ${ }^{47}$. Embora esses autores tenham feito as análises em sistemas separados, é possível usar os detectores UV e IR em série para execução da multianálise.

\section{CLAE-EM}

A partir da década de 80 , ocorreu um crescimento rápido na multianálise de compostos não voláteis em fluidos biológicos, particularmente, sangue e urina. Em alguns setores, como por ex. em medicina forense, havia a necessidade de se usar um método que possibilitasse a identificação inequívoca de um determinado composto. A CLAE-UV não atendia integralmente a essa exigência, em função da possibilidade de co-eluição de interferentes com o analito, que poderia passar despercebido, alterando o resultado final. Isto certamente produziu conflitos que geraram recursos administrativos e até judiciais. O maior avanço da CLAE foi seu acoplamento à EM. Esta técnica hifenada permitiu a análise simultânea de compostos não voláteis através dos seus espectros de massas. O uso da CLAE-EM possibilitou a análise de quantidades diminutas de metilxantinas, com boa precisão e exatidão, em plantas e fluidos biológicos, fornecendo um diagnóstico da estrutura química desses compostos.

Setchell et al..$^{48}$ descreveram um método para análise de cafeína na saliva e no soro baseado na CLAE-EM. A cafeína foi isolada por extração em fase sólida em um cartucho com fase $\mathrm{C}_{18}$, sendo eluída com metanol. A separação cromatográfica foi conduzida em coluna de fase reversa, no modo isocrático, com fase móvel constituída de acetato de amônio 0,1 M, pH = 4,6 e acetonitrila (85:15, v/v). Sakairi e Kambara ${ }^{49}$ usaram a CLAE-EM com uma interface de ionização química à pressão atmosférica (IQPA) para a multianálise de diversas classes de compostos não voláteis, dentre elas as metilxantinas. $\mathrm{O}$ método IQPA tem uma sensibilidade moderada devido à fragmentação reduzida, o que é resultado das condições brandas de ionização. A cafeína mostrou o íon pseudo-molecular $m / z$ 195, enquanto a teofilina e a teobromina mostraram o íon pseudo-molecular $\left(\mathrm{MH}^{+}, \mathrm{m} / \mathrm{z}, 181\right)$. Gardinali e Zhao ${ }^{50}$ também usaram a CLAE-IQPA/EM para analisar cafeína em águas superficiais de alguns sistemas costeiros localizados na Flórida. O método permitiu a determinação de cafeína no limite de detecção de 4,0 ng L ${ }^{-1}$. Hieda et $a l .{ }^{51}$ analisaram metilxantinas em plasma e urina através da CLAE/EM. As metilxantinas foram isoladas por extração em fase sólida com coluna do tipo extrelut ${ }^{R} 1$. Esses autores usaram um cromatógrafo líquido acoplado a um EM com bombardeamento de átomos do tipo "frit-fast". Este sistema possibilitou uma análise menos sensível, alcançando níveis de detecção da ordem de $5 \mu \mathrm{g} \mathrm{L}^{-1}$. A teobromina e a teofilina mostraram o mesmo íon pseudo-molecular $m / z 181$, porém somente a teofilina apresentou o fragmento minoritário $\mathrm{m} / \mathrm{z}$ 124. A CLAE-DAD-ionização por "electrospray" (IES)/EM foi aplicada para multianálise de alcalóides purínicos e compostos fenólicos em amostras de chá ${ }^{52}$. O uso deste sistema com informação multidimensional permitiu a análise simultânea de compostos com estruturas químicas diferentes, sem a necessidade de pré-tratamento da amostra. O conteúdo de teanina e catequinas foi medido pelo uso do $\mathrm{DAD}$, enquanto ácido clorogênico, cafeína e outras metilxantinas pela IES/EM.

Mais recentemente, a CLAE-EM/EM foi usada para determinação de metabólitos da cafeína em urina, sem preparação prévia da amostra $^{53}$. Cerca de 11 compostos foram analisados, dentre estes teofilina e ácido 1-metilúrico. A ausência de um método de extração simplificou e acelerou a multianálise de diversos compostos, sem prejudicar parâmetros como precisão e exatidão. Weimann et al. ${ }^{54}$ também aplicaram a CLAE-EM/EM para análise de cafeína e seus metabólitos em urina. Todavia, esses autores procederam à diluição e centrifugação da amostra antes da injeção no cromatógrafo. Del Rio et al. ${ }^{55}$ usaram a CLAE-EM/EM para análise de cafeína, teobromina e 30 compostos fenólicos em chás verde e preto. As infusões de chá foram filtradas e injetadas em coluna de fase reversa sem qualquer tipo de extração prévia dos compostos. A ausência de prétratamento da amostra é particularmente importante, quando se necessita de um método de rotina para analisar uma quantidade expres- 
siva de amostras, tornando a CLAE-EM/EM uma técnica conveniente em laboratórios de rotina. Entretanto, a ausência de pré-tratamento das amostras diminui consideravelmente o tempo de vida das colunas, aliado ao fato de que o custo de um equipamento de CLAE$\mathrm{EM} / \mathrm{EM}$ inviabiliza sua aquisição em laboratórios de pequeno porte.

\section{Eletroforese capilar}

A eletroforese capilar é uma técnica valiosa para a multianálise de compostos de baixa MM em diferentes matrizes. Este método é preciso e exato, a resolução dos compostos é excelente devido à alta eficiência de separação e requer um volume de amostra da ordem de alguns nanolitros. Jimidar et al. ${ }^{56}$ usaram a eletroforese capilar de zona (ECZ) para determinar cafeína e edulcorantes em bebidas dietéticas. A fase móvel consistiu de tampão fosfato a $\mathrm{pH}=11$. A detecção foi conduzida pela análise da absorvância na região do UV. Esses autores compararam a ECZ com a CLAE e concluíram que a ECZ mostrou uma eficiência de separação 60 vezes maior, enquanto a CLAE foi mais sensível, apresentando um limite de detecção 10 vezes maior. Jin et al. ${ }^{57}$ também usaram a ECZ para determinação de cafeína em soro e bebidas. A fase móvel foi composta de tampão fosfato produzido pela mistura de di-hidrogenofosfato de sódio 0,152 mmol L ${ }^{-1}$ e hidrogenofosfato de sódio $0,648 \mathrm{mmol} \mathrm{L}^{-1}$ a $\mathrm{pH} \cong 7,8$ e a detecção foi conduzida por análise potenciométrica.

A eletrocromatografia capilar micelar, também chamada de cromatografia capilar eletrocinética micelar (CCEM), é o tipo de eletroforese capilar mais usada para multianálise de metilxantinas. É a técnica geralmente usada para separação de compostos neutros. A CCEM inclui a adição de um surfactante, como o dodecil-sulfato de sódio, sendo o analito separado pela sua partição entre as micelas e o tampão. A CCEM foi usada para separar cafeína e outros derivados da purina em amostras de saliva, soro e urina ${ }^{58}$. A fase móvel foi constituída de tampão borato-fosfato a $\mathrm{pH} \cong 9$ contendo $75 \mathrm{mmol} \mathrm{L}^{-1}$ de dodecil-sulfato de sódio. Os resultados foram bem satisfatórios, inclusive alíquotas da saliva ou do soro foram aplicadas diretamente sem qualquer prétratamento da amostra. Korman et al. ${ }^{59}$ usaram a CCEM para monitorar a qualidade de formulações farmacêuticas compostas de derivados da xantina. Esses autores obtiveram resultados satisfatórios na determinação de impurezas, como cafeína e xantina em preparações contendo efedrina e mebrofenoidramina. Zhao e Lunte ${ }^{60}$ avaliaram a eficiência de separação da cafeína e de seus metabólitos teofilina, teobromina e paraxantina através da CCEM. A resolução e a reprodutibilidade foram satisfatórias e somente 2 min foram consumidos para se efetuar a análise. Lai e Dabek-Zlotorzynska ${ }^{61}$ testaram várias composições de fase móvel para separação de metilxantinas e outros compostos purínicos através da CCEM. Uma separação ótima foi obtida com o uso de uma fase ternária constituída de isopropanol/hexano/TRIS $1 \mathrm{mmol} \mathrm{L}^{-1}$ $(52: 40: 8, \mathrm{v} / \mathrm{v}, \mathrm{pH}=8)$. Pomilio et al. ${ }^{62}$ usaram a CCEM para análise simultânea de metilxantinas e ácido clorogênico em 30 amostras de erva-mate. Os compostos alvo foram detectados pela análise da absorvância na região do UV através do DAD. Em adição, cada composto foi coletado separadamente e analisado por EM. A CCEM foi otimizada para análise simultânea de cafeína, paracetamol e ácido acetilsalicílico em formulações farmacêuticas ${ }^{63}$. A mistura de formiato de amônio $\left(25 \mathrm{mmol} \mathrm{L}^{-1}, \mathrm{pH}=3\right)$ e acetonitrila $(30: 70, \mathrm{v} / \mathrm{v})$ foi usada como fase móvel. A detecção foi conduzida no comprimento de onda de $210 \mathrm{~nm}$. A CCEM também foi aplicada na multianálise de flavonóides monoméricos (catequina e epicatequina) e metilxantinas (cafeína e teobromina) em chocolate e cacau ${ }^{64}$. Devido à baixa estabilidade das catequinas em $\mathrm{pH}$ alcalino, o procedimento analítico foi conduzido em $\mathrm{pH}$ ácido $(\mathrm{pH}=2,5)$.

Sombra et al. ${ }^{65}$ realizaram um estudo comparativo entre eletroforese capilar e CLAE para análise de cafeína e outros compostos no guaraná.
Com relação aos parâmetros de sensibilidade, precisão e especificidade, os métodos são equivalentes. Todavia, o tempo de análise da eletroforese capilar é 2 vezes menor que o da CLAE. Além do mais, o consumo de solvente na CLAE é 100 vezes maior.

\section{Quimiometria}

A quimiometria é uma ferramenta matemática valiosa que, em combinação com diferentes métodos químicos, possibilita a análise de um grande número de variáveis em uma única amostra. Nos últimos 20 anos, com o interfaceamento de instrumentos aos computadores, houve um crescente interesse pela aplicação da calibração multivariada para resolução de problemas decorrentes da multianálise de analitos. Nesse contexto, os métodos de regressão de mínimos quadrados parciais (PLS) e de componentes principais (PCR) têm recebido maior atenção como técnicas de calibração, já que simplificam consideravelmente a manipulação da amostra ${ }^{66}$. Com relação ao tratamento de dados multivariados, a análise de componentes principais (PCA) é o método quimiométrico mais importante, porque permite que a natureza multivariada dos dados seja visualizada em poucas dimensões ${ }^{67}$. Embora a abordagem quimiométrica seja usada na multianálise de analitos em diferentes matrizes, ela é aplicada freqüentemente na análise de formulações farmacêuticas contendo 2 ou mais compostos cujos espectros estão sobrepostos.

Dinc e Baleanu ${ }^{68}$ usaram o PCR e o método clássico de mínimos quadrados (CLS) para multianálise de formulações farmacêuticas contendo acetaminofeno e cafeína. As calibrações quimiométricas foram preparadas pela medição de valores de absorvância na região espectral de 215-285 nm. Esses autores compararam seus resultados com aqueles obtidos previamente com a CLAE. Os métodos apresentaram resultados similares, porém o uso da CLAE exigiu a aplicação prévia de um método químico de separação, enquanto o método espectrofotométrico com calibração multivariada não. Tanto o PCR como o PLS e o método dos mínimos quadrados invertidos (ILS) foram aplicados para multianálise e teste de dissolução de comprimidos contendo uma mistura de paracetamol, propilfenazona e cafeína ${ }^{69}$. Nenhum método de separação dos analitos foi usado na matriz. Os resultados da absorvância da matriz foram obtidos na região espectral de 210-310 nm. Todos os três métodos quimiométricos apresentaram resultados satisfatórios, tanto para o teste de dissolução como para multianálise. A análise simultânea do ácido acetilsalicílico (AAS) e da cafeína em matrizes sólidas foi conduzida pelo uso da espectrofluorimetria acoplada à técnica da calibração multivariada PLS-1, a qual é uma variante da PLS ${ }^{70}$. Embora o AAS e a cafeína apresentem bandas espectrais sobrepostas, a aplicação do método espectrofluorimétrico para análise desses 2 compostos em formulações farmacêuticas produziu resultados satisfatórios em menor tempo e com boa precisão. Uma vez que os parâmetros de calibração são estabelecidos, é necessário apenas proceder à leitura do espectro de fluorescência na matriz sólida, a qual não precisa ser submetida a qualquer método prévio de separação química ${ }^{70}$.

\section{Espectroscopia de infravermelho (IV)}

Nos últimos anos, a técnica de espectroscopia na região do IV tem apresentado resultados muito interessantes quando aplicada nas áreas farmacêutica e de alimentos. Nesse contexto, deve-se destacar o uso dos espectrômetros de IV com transformadas de Fourier (IVTF) e seu emprego na identificação e dosagem de cafeína em medicamentos, chás e café. Bouhsain et al. ${ }^{71}$ usaram a IVTF para determinação simultânea de propifenazona e cafeína em fármacos. O método consistiu na dissolução dos princípios ativos em clorofórmio, seguida pela filtração das soluções para remoção dos excipientes. A propifenazona foi determinada por medidas de absorvância a 1595 
$\mathrm{cm}^{-1}$, com uma linha de base estabelecida entre 2000 e $890 \mathrm{~cm}^{-1}$, e a cafeína através do emprego dos valores da primeira derivada a 1712 $\mathrm{cm}^{-1}$. Foram usadas, em ambos os casos, soluções independentes dessas duas substâncias para calibração externa. Já Ohnsmann et al. ${ }^{72}$ utilizaram a técnica de IVTF para determinação de cafeína em extratos de folhas de chá. O método baseou-se na extração com amônia e clorofórmio e na determinação direta do teor de cafeína nos extratos de clorofórmio, pelo uso das medidas de absorvância associadas às alturas dos picos obtidos a $1658,5 \mathrm{~cm}^{-1}$ e por calibração externa. O método apresentou um limite de detecção de $1 \mathrm{mg} \mathrm{L}^{-1}$, correspondendo a $0,002 \%(\mathrm{~m} / \mathrm{m})$ de cafeína nas folhas de chá. O tempo necessário para realização da análise de uma única amostra foi de apenas 15 min. Paradkar e Irudayaraj ${ }^{73}$ usaram a espectroscopia de IVTF para determinar o conteúdo de metilxantinas no chá e no café pelo uso de um modelo de calibração único. O espectro de IVTR da cafeína pura foi caracterizado e as regiões espectrais de 1500-1800 e de 2800$3000 \mathrm{~cm}^{-1}$ foram usadas para as determinações quantitativas com o auxílio dos métodos de regressão PLS e PCR. A utilização dessa técnica de espectroscopia associada à quimiometria permitiu a determinação do conteúdo de cafeína de modo acurado com um valor de $\mathrm{R}^{2}$ superior a 0,99. Anteriormente, a espectroscopia de IVTF em associação com a quimiometria já havia sido explorada por Briandet et $a l .{ }^{74}$, como um método alternativo aos métodos químicos úmidos para discriminação e quantificação do conteúdo dos cafés Arábica e Robusta em misturas de café instantâneo seco por liofilização. Os espectros foram obtidos através de duas técnicas: IVTR por reflexão difusa e por reflexão total atenuada. A análise do PCA foi aplicada sobre esses espectros, permitindo a discriminação entre as espécies de café Arábica e Robusta. Os autores concluíram que essa discriminação foi baseada, principalmente, nos conteúdos diferentes de cafeína e ácido clorogênico em cada espécie. A cafeína foi responsável pelas bandas na região entre $1550-1750 \mathrm{~cm}^{-1}$ e o ácido clorogênico apresentou suas principais bandas na região entre $1150-1300 \mathrm{~cm}^{-1}$. Em um outro estudo ${ }^{75}$, foi descrito o uso da espectroscopia de reflexão difusa no IV próximo associada à PLS para multianálise de cafeína, trigonelina e ácido clorogênico em amostras de café verde. Os resultados obtidos com essa técnica espectroscópica foram comparados com aqueles obtidos com o método de CLAE com coluna de permeação em gel descrito previamente na literatura ${ }^{46}$. A técnica de espectroscopia do IV associada à quimiometria apresentou algumas vantagens, tais como pouca manipulação da amostra, não destruição da matriz e não produção de resíduos químicos durante a análise.

\section{Eletroanálise}

Dentre os processos eletroanalíticos já descritos na literatura com o objetivo de dosar cafeína, a voltametria/polarografia de pulso diferencial e a de onda quadrada merecem destaque. Na polarografia de pulso diferencial, todos os pulsos têm a mesma magnitude e a corrente é medida antes da aplicação do pulso e no final do período de cada pulso. A primeira corrente é subtraída da segunda, o que gera uma curva derivativa, em "forma de sino". Esse tipo de técnica foi utilizado por Sontag e $\mathrm{Kral}^{76}$ para determinação de cafeína em bebidas de cola, café e chá, após sua oxidação em um eletrodo de carbono vítreo em $\mathrm{pH}$ 1,2. Os resultados da voltametria mostraram-se bem semelhantes aos obtidos através da CLAE. Posteriormente, $\mathrm{Kral}^{77}$ criou um método para determinação de cafeína em bebidas, utilizando a polarografia de pulso diferencial. A análise foi conduzida por voltametria anódica de pulso diferencial em um eletrodo de carbono vítreo. O limite de detecção foi de $0,5 \mathrm{mg} \mathrm{L}^{-1} \mathrm{em} \mathrm{pH} \mathrm{1,2.} \mathrm{Já} \mathrm{Lau} \mathrm{et} \mathrm{al.}{ }^{78}$ empregaram a voltametria de pulso diferencial como um método simples, rápido e acurado para análise simultânea de ácido ascórbico, cafeína e paracetamol em fármacos. As correntes de pico para ácido ascórbico, paracetamol e cafeína foram medidas com um eletrodo de carbono vítreo a $+0,350$; $+0,618$ e $+1,425 \mathrm{~V}$, respectivamente, contra um eletrodo de calomelano saturado. Uma mistura contendo ácido perclórico $(0,1 \mathrm{M})$ e metanol, na mesma razão, foi usada como solvente e eletrólito de suporte. A amplitude de modulação ótima, o tempo de repetição do pulso e a taxa de varredura do analisador polarográfico foram, respectivamente, 50 $\mathrm{mV}, 0,5 \mathrm{~s} \mathrm{e} 5 \mathrm{mV} \mathrm{s}^{-1}$. As faixas de calibração linear para ácido ascórbico, cafeína e paracetamol foram, respectivamente, de 0 - 35, 0 - 50 e 0 $55 \mathrm{mg} \mathrm{mL}^{-1}$. A voltametria de onda quadrada é uma técnica que permite varreduras rápidas, com excelente distinção entre as correntes capacitiva e faradaica. Normalmente, apresenta sensibilidade um pouco superior à obtida na polarografia de pulso diferencial, com a vantagem adicional de permitir medições com altas velocidades. Esse tipo de técnica foi utilizada por JyhMyng et al. ${ }^{79}$ para determinação de cafeína em bebidas de chá, café e cola com um eletrodo quimicamente modificado (EQM) de Nafion/pirocloro-óxido de rutênio. O termo EQM é usado em eletroquímica para designar eletrodos com espécies quimicamente ativas convenientemente imobilizadas em sua superfície ${ }^{80}$. No caso em questão, o uso desse EQM produziu um incremento marcante na resposta da corrente quando comparado com o eletrodo de carbono vítreo não revestido ${ }^{79}$. Uma curva analítica linear foi obtida sobre a faixa de 5 - $200 \mu \mathrm{M}$ em uma solução de $\mathrm{HClO}_{4}$ 0,05 M com um limite de detecção de $2 \mu \mathrm{M}$. Em outro estudo ${ }^{81}$, foi usado um eletrodo comercial simples de grafite (GPE) para monitorar cafeína através de um método de voltametria de onda quadrada de redissolução anódica. De modo geral, devido a sua alta sensibilidade e baixo limite de detecção, a eletroanálise de redissolução é particularmente útil e popular nas determinações de compostos em baixas concentrações ${ }^{82-85}$. No exemplo em questão ${ }^{81}$, esse método foi aplicado para determinar os níveis de cafeína em várias amostras de chá, o que rendeu um erro relativo de $1 \%$ na concentração. A cafeína foi depositada a zero Volts (contra $\mathrm{Ag} / \mathrm{AgCl}$ ), depois reduzida a $+1,40 \mathrm{~V}$ para removê-la do GPE. As condições experimentais ótimas para a análise foram as seguintes: meio com $\mathrm{pH}=9$, potencial de deposição de zero Volts, tempo de deposição de 120 s, frequiência de onda quadrada de $25 \mathrm{~Hz}$, amplitude de onda quadrada de $45 \mathrm{mV}$ e potencial de etapa de $6 \mathrm{mV}$. Nessas condições ótimas, uma faixa linear foi observada dentro das concentrações de $0-500 \mathrm{mg} \mathrm{L}^{-1}$. O limite de detecção foi 9,2 $\mathrm{mg} \mathrm{L}^{-1}$, que é comparável com o resultado obtido usando-se um eletrodo de pasta de carbono $\left(8,2 \mathrm{mg} \mathrm{L}^{-1}\right)$. Por último, devemos mencionar o uso de biossensores enzimáticos para dosagem de cafeína. Um biossensor é um dispositivo capaz de fornecer informação analítica quantitativa ou semiquantitativa, usando um elemento de reconhecimento de origem biológica, o qual está em contato direto com um elemento de transdução. O elemento de transdução deve ser capaz de converter a resposta química em um sinal mensurável apropriado ${ }^{86}$. Nesse contexto, Pizzariello et al. ${ }^{87}$ desenvolveram um método de biossensor prático e de baixo custo para detecção de cafeína em café. Nesse caso, um eletrodo potenciométrico sensível a variações de $\mathrm{pH}$ foi usado para detectar mudanças de $\mathrm{pH}$ resultantes da inibição, pela cafeína, da ação da fosfodiesterase de nucleotídeo 3',5'-cíclico sobre a hidrólise do AMP cíclico. O método foi efetivo na detecção de cafeína em concentrações de 0 - $4 \mathrm{mg} \mathrm{L}^{-1}$ e o desvio padrão para 5 medidas de uma solução de cafeína a $0,2 \mathrm{mg} \mathrm{mL}^{-1}$ foi de $\pm 7,1 \mu \mathrm{g} \mathrm{mL}^{-1}$. O limite de detecção foi de $0,6 \mathrm{mg} \mathrm{mL}^{-1}$. Os resultados da análise de amostras de café expresso com o método do biossensor mostraram-se similares aos valores obtidos usando-se a CLAE.

\section{CONCLUSÃO}

Os métodos gravimétricos e "Bailey-Andrew"16 são de custo baixo, porém tediosos e de padronização muito difícil, sendo considerados como métodos semi-quantitativos. Contudo, a maior limitação desses métodos está no fato de produzirem resultados superes- 
timados, já que compostos interferentes, presentes no extrato clorofórmio, são contabilizados como cafeína. Ambas as técnicas estão em desuso há algum tempo.

O desenvolvimento do método espectrofotométrico de absorção na região do UV propiciou um salto qualitativo na análise de cafeína em comparação aos 2 métodos supracitados. Primeiro, porque os extratos foram tratados com agentes clarificantes, o que reduziu o conteúdo de interferentes. Segundo, porque análise da cafeína no comprimento de onda específico de $272 \mathrm{~nm}$ aumentou a seletividade do método e, portanto, sua precisão e exatidão. Entretanto, não foi possível eliminar todos os interferentes, particularmente compostos fenólicos, que também absorvem no comprimento de $272 \mathrm{~nm}$.

O método cromatográfico-espectrofotométrico além de ter alta precisão e exatidão, como demostrado por estudos inter-laboratoriais, permite a obtenção de extratos mais límpidos, já que a cromatografia líquida clássica é usada para clarificar os extratos. Este método é barato, simples e tem precisão satisfatória, porém consome muito tempo. Ele é o método apropriado para análise de cafeína quando não se tem acesso a métodos que utilizam equipamentos de custo elevado, como por ex., a CLAE e a eletroforese capilar.

A técnica de cromatografia em camada delgada de alta eficiência para análise de cafeína é rápida e com boa precisão, porém não foi, ainda, validada por análises inter-laboratoriais. Também seria importante comparar seus resultados com aqueles de outros métodos comumente usados para análise de cafeína. O método de cromatografia em camada delgada de alta eficiência é ainda pouco difundido, o que pode ser constatado pelo menor número de publicações científicas.

A CG é rápida e tem alta precisão e sensibilidade, particularmente, a CG/EM. Entretanto, o número de trabalhos científicos que aborda a análise de cafeína pela CG é muito baixo. O custo elevado para aquisição de um equipamento de CG, principalmente a CG/ EM, é o primeiro fator limitante para seu uso. Por outro lado, o extrato obtido das amostras tem uma fração não volátil, rica em macromoléculas, como no caso do café processado. Desta forma, a etapa de limpeza torna-se complexa, já que a presença desses compostos nos sistemas de injeção e separação do CG provoca interferências sérias na análise, bem como reduz o tempo de vida útil desses sistemas. Além do mais, a cafeína e outras metilxantinas necessitam de um passo prévio de derivatização antes da análise por CG. Certamente este último é o fator determinante para o menor uso desta técnica na análise de cafeína.

O uso da cromatografia de troca iônica para análise de cafeína mostrou resultados satisfatórios. Entretanto, o método consome muito tempo e as condições cromatográficas podem variar consideravelmente, em função da composição química das matrizes a serem analisadas.

O emprego da CLAE-UV para determinação de cafeína foi um salto qualitativo importante no que diz respeito aos parâmetros de precisão, exatidão e rapidez na análise. Também permitiu pela primeira vez a multianálise de metilxantinas, como cafeína, teofilina (1,3-dimetilxantina) e teobromina (3,7-dimetilxantina). Com o desenvolvimento da CLAE-UV/DAD a multianálise de metilxantinas melhorou em termos de precisão e exatidão, já que cada alcalóide foi analisado no seu comprimento de onda máximo de absorção. Embora o equipamento tenha custo elevado, a técnica é usada comumente para análise de cafeína em alimentos e fluidos biológicos. A principal limitação da CLAE-UV é a necessidade de uma preparação extensiva da amostra. Esta estratégia é essencial para se eliminar interferentes nas matrizes, particularmente nos fluídos biológicos, que co-eluem com a cafeína e, também, absorvem na mesma faixa de comprimento de onda.

A CLAE com coluna de permeação em gel acoplada com detector de UV ou de IR é um poderoso método analítico, que permite a análise simultânea de compostos de baixa MM. O método usa água como fase móvel, o que reduz o custo com manutenção do equipamento e a contaminação por solventes orgânicos. Além disso, o método é preciso, exato e de fácil reprodução, podendo ser usado em análises de rotina. Entretanto, o preço deste tipo de coluna ainda é alto. Além disso, a validação completa do método não foi implementada, o que pode ser constatado pela ausência de análises inter-laboratoriais.

Uma das vantagens da CLAE/EM é permitir a multianálise de compostos não voláteis, com estruturas químicas diferentes, sem a necessidade de derivatização dos analitos, como no caso da CG/EM. Um segundo ponto relevante desta técnica é permitir o uso de métodos mais simples para pré-tratamento da amostra, sendo possível, em alguns casos, a eliminação completa de qualquer método de extração dos analitos. Desta forma, o método é rápido e fornece uma identificação inequívoca da cafeína, com alta precisão, exatidão e sensibilidade. Em setores cuja análise quantitativa da cafeína precisa ser acompanhada da identificação inequívoca de sua estrutura química, como é o caso da medicina forense, a CLAE/EM é essencial. Embora o custo do equipamento ainda seja bastante elevado, certamente esta técnica deverá se constituir em uma das mais importantes ferramentas para análise de cafeína e de outras metilxantinas.

A eletroforese capilar, com detecção na região do UV, é uma ferramenta valiosa na separação simultânea de metilxantinas e outros compostos com funções químicas diversas. Apresenta sensibilidade, precisão e exatidão satisfatórias. O tempo de análise e o consumo de solventes orgânicos é geralmente menor que os obtidos com a CLAE. Muito embora a eletroforese capilar acoplada à EM já esteja comercialmente disponível, seu uso ainda é pouco difundido.

A combinação da quimiometria com diferentes técnicas espectroscópicas permite a análise de dados químicos de natureza multivariada. Certos compostos apresentam espectros sobrepostos ao da cafeína, o que dificulta apreciavelmente a análise espectrofotométrica quantitativa. Nesse caso, a abordagem quimiométrica é usada na resolução desses problemas. Um aspecto importante é a dispensa do uso de passos prévios de separação e derivatização química. Isto reduz consideravelmente o tempo de análise e o consumo de reagentes, sem afetar a precisão, sendo atrativo para análises em larga escala, particularmente, de formulações farmacêuticas.

A espectroscopia de IV é vantajosa porque possibilita que a análise dos analitos ocorra com pouca manipulação da amostra, inclusive não havendo destruição da matriz. Em alguns setores, como por ex. na medicina forense e na área criminal, a não destruição da amostra é um aspecto relevante a ser considerado durante a execução do processo analítico. Uma outra vantagem da espectroscopia de IV é que não há produção de resíduos químicos durante a análise. Além disso, permite a obtenção de espectros de pós, sólidos e espécies químicas adsorvidas em sólidos. A espectroscopia de IV permite a identificação e dosagem acurada de vários compostos em matrizes farmacológicas e alimentares complexas. $\mathrm{O}$ estabelecimento do teor de alguns desses compostos pode servir como ferramenta para controle de qualidade e caracterização desses produtos. Sua associação com a quimiometria tem mostrado ser uma importante ferramenta na multianálise de compostos nas mais diversas matrizes, por sua precisão e praticidade.

Os métodos eletroanalíticos para dosagem de cafeína e compostos análogos em matrizes complexas, como alimentos e drogas, são considerados de menor custo, de rápida execução e, geralmente, não necessitam de um pré-tratamento da amostra. Apesar disso, os métodos eletroanalíticos têm sido pouco utilizados na análise de cafeína quando comparados à CG e CLAE. Recentemente, o uso de EQM e biossensores enzimáticos tem se mostrado muito útil em aplicações analíticas. A modificação química do eletrodo visa controlar a natureza físico-química da interface eletrodo/solução como uma forma de alterar a reatividade e seletividade do sensor base, 
favorecendo assim o desenvolvimento de eletrodos para vários fins e aplicações, desde a catálise de reações orgânicas e inorgânicas até a transferência de elétrons em moléculas de interesse. Já no caso dos biossensores enzimáticos, a combinação da seletividade e sensibilidade da enzima com a simplicidade dos transdutores eletroquímicos é altamente vantajosa. O desenvolvimento dessas duas últimas técnicas, provavelmente, deverá incrementar a utilização desses métodos eletroanalíticos na análise de cafeína e outros compostos químicos em diferentes matrizes nos próximos anos.

\section{REFERÊNCIAS}

1. De Maria, C. A. B.; Trugo, L. C.; Cora, G.; Quim. Nova 1996, 19, 350.

2. Bucci, L. R.; Am. J. Clin. Nutr. 2000, 72, 624S

3. Caudle, A. G.; Yifang, G.; Bell, L. N.; Food Res. Int. 2001, 34, 599.

4. de Andrade, J. B.; Pinheiro, H. L. C.; Lopes, W. A.; Martins, S.; Amorim, A. M. M.; Brandão, A. M.; Quim. Nova 1995, 18, 379.

5. Castellanos, F. X.; Rapoport, J. L.; Food Chem. Toxicol. 2002, 40, 1235.

6. Smith, A.; Food Chem. Toxicol. 2002, 40, 1243.

7. Lorist, M. M.; Brain Cogn. 2003, 53, 82.

8. Frishman, W. H.; Del Vecchio, A.; Sanal, S.; Ismail, A.; Heart Dis. 2003, $5,253$.

9. Richardson, T.; Rozkovec, A.; Thomas, P.; Ryder, J.; Meckes, C.; Kerr, D.; Diabetes Care 2004, 27, 1127.

10. James, J. E.; Psychosom. Med. 2004, 66, 63.

11. Lovallo, W. R.; Wilson, M. F.; Vincent, A. S.; Sung, B. H.; Mckey, B. S.; Whitsett, T. L.; Hypertension 2004, 43, 760.

12. Karatzis, E.; Papaioannou, T. G.; Aznaouridis, K.; Karatzi, K.; Stamatelopoulos, K.; Zampelas, A.; Papamichael, C.; Lekakis, J.; Mavrikakis, M.; Int. J. Cardiol. 2005, 98, 425.

13. Heaney, R. P.; Food Chem. Toxicol. 2002, 40, 1263.

14. Nawrot, P.; Jordan, S.; Eastwood, J.; Rotstein, J.; Hugenholtz, A.; Feeley, M.; Food Addit. Contam. 2003, 20, 1.

15. A.O.A.C.; Official and Tentative methods of Analysis, Association of Official Agricultural Chemists, $6^{\text {th }}$ ed., Pennsylvania, 1945

16. A.O.A.C.; J. Assoc. Off. Agr. Chem. 1947, 30, 70.

17. Hartley, W. N.; J. Chem. Soc. Trans. 1905, 87, 1796.

18. Holiday, E. R.; Biochem. J. 1930, 24, 619.

19. Ishler, N. H.; Finucane, T. P.; Borker, E.; Anal. Chem. 1948, $20,1162$.

20. Yeransian, J. A.; Kadin, H.; Borker, E.; Stefanucci, A.; J. Assoc. Off. Ana. Chem. 1963, 46, 315.

21. Borker, E.; J. Assoc. Off. Ana. Chem. 1963, 46, 319.

22. Levine, J.; J. Assoc. Off. Ana. Chem. 1962, 45, 254.

23. Smith, R. F.; Rees, D. I.; Analyst 1963, 88, 310.

24. Newton, J. M.; J. Assoc. Off. Ana. Chem. 1979, 62, 705.

25. Harlos, H.; Lebensm. Ind. 1973, 20, 412.

26. Abourashed, E. A.; Mossa, J. S.; J. Pharm. Biomed. Anal. 2004, 36, 617.

27. Vitzthum, O. G.; Barthels, M.; Kwasny, H.; Z. Lebensm. Unters. Forsch. 1974, 157, 135.

28. Strahl, N. R.; Lewis, H.; Fargen, R.; J. Agric. Food Chem. 1977, $25,233$.

29. Thomas, P. M.; Foster, G. D.; J. Environ. Sci. Health, Part A: Toxic/Hazard Subst. Environ. Eng. 2004, 39, 1969.

30. Murgia, E.; Richards, P.; Walton, H. F.; J. Chromatogr. 1973, 87, 52331.

31. Madison, B. L.; Kozarek, W. J.; Damo, C. P.; J. Assoc. Off. Ana. Chem. 1976, 59, 1258

32. Kreiser, W. R.; Martin Jr, R. A.; J. Assoc. Off. Ana. Chem. 1978, 61, 1424.

33. Ashoor, S. H.; Seperich, G. J.; Monte, W. C.; Welty, J.; J. Assoc. Off. Ana. Chem. 1983, 66, 606.

34. Trugo, L. C.; Macrae, R.; Dick, J.; J. Sci. Food Agric. 1983, 34, 300.

35. Muhtadi, F. J.; El-Hawary, S. S.; Hifnawy, M. S.; J. Liq. Chromatogr. 1990, $13,1013$.

36. Nakakuri, H.; Horie, H.; Yamauchi, Y.; Kohata, K.; J. Chromatogr., A 1999, $848,523$.

37. Horie, H.; Nesumi, A.; Ujihara, T.; kohata, K.; J. Chromatogr., A 2002, 942, 271.

38. Casal, S.; Oliveira, M. B.; Ferreira, M. A.; Food Chem. 1998, $21,3187$.

39. Casal, S.; Oliveira, M. B.; Ferreira, M. A.; Food Chem. 2000, 68, 481.

40. Ventura, R.; Jimenez, C.; Closas, N.; Segura, J.; De la Torre, R.; J. Chromatogr., B: Anal. Technol. Biomed. Life Sci. 2003, 795, 167.

41. Emara, S.; Biomed. Chromatogr. 2004, 18, 479.
42. Zydron, M.; Baranowski, J.; Baranowska, I.; J. Sep. Sci. 2004, 27, 1166. 43. Zambonin, C. G.; Aresta, A.; Palmisano, F.; J. Pharm. Biomed. Anal. 2004, $36,621$.

44. Müller, E.; Jork, H.; Deut. Lebensm-Rundsch. 1990, 86, 243.

45. Trugo, L. C.; De Maria, C. A. B.; Werneck, C. C.; Food Chem. 1991, 42, 81.

46. De Maria, C. A. B.; Trugo, L. C.; Moreira, R. F. A.; Petracco, M.; Food Chem. 1995, 52, 447.

47. De Maria, C. A. B.; Moreira, R. F. A.; Quim. Nova 2004, 27, 586.

48. Setchell, K. D. R.; Welsh, M. B.; Klooster, M. J.; Balistreri, W. F.; Lim, C. K.; J. Chromatogr., A 1987, 385, 267.

49. Sakairi, M.; Kambara, H.; Anal. Chem. 1988, 60, 774.

50. Gardinali, P. R.; Zhao, X.; Environ. Int. 2002, $28,521$.

51. Hieda, Y.; Kashimura, S.; Hara, K.; Kageura, M.; J. Chromatogr., A 1987, $385,267$.

52. Zhu, X.; Chen, B.; Ma, M.; Luo, X.; Zhang, F.; Yao, S.; Wan, Z.; Yang, D.; Hang, H.; J. Pharm. Biomed. Anal. 2004, 34, 695.

53. Schneider, H.; Ma, L.; Glatt, H.; J. Chromatogr., B: Anal. Technol. Biomed. Life Sci. 2003, 789, 227.

54. Weimann, A.; Sabroe, M.; Poulsen, H. E.; J. Mass Spectrom. 2005, 40, 307.

55. Del Rio, D.; Stewart, A. J.; Mullen, W.; Burns, J.; Lean, M. E. J.; Brighenti, F.; Crozier, A.; J. Agric. Food Chem. 2004, 52, 2807.

56. Jimidar, M.; Hamoir, T. P.; Foriers, A.; Massart, D. L.; J. Chromatogr., A 1993, 636, 179.

57. Jin, W.; Yu, D.; Dong, Q.; J. Chromatogr. Sci. 2000, 38, 11.

58. Thormann, W.; Minger, A.; Molteni, S.; Caslavska, J.; Gebauer, P.; J. Chromatogr., A 1992, 593, 275.

59. Korman, M.; Vindevoguel, J.; Sandra P.; Electrophoresis 1994, 15, 1304.

60. Zhao, Y.; Lunte, C. E.; J. Chromatogr., B: Anal. Technol. Biomed. Life Sci. 1997, 688, 265.

61. Lai, E. P.; Dabek-Zlotorzynska, E.; Electrophoresis 1999, 20, 2366.

62. Pomilio, A. B.; Trajtemberg, S.; Vitale, A. A.; Phytochem. Anal. 2002, 13, 235.

63. Pucci, V.; Mandrioli, R.; Raggi, M. A.; Fanali, S.; Electrophoresis 2004, 25,615 .

64. Gotti, R.; Fiori, J.; Mancini, F.; Cavrini, V.; Electrophoresis 2004, 25, 3282.

65. Sombra, L. L.; Gomez, M. R.; Olsina, R.; Martinez, L. D.; Silva, M. F.; J. Pharm. Biomed. Anal. 2005, 36, 989.

66. Bautista, R. D.; Aberasturi, F. J.; Jimenez, A. I.; Jimenez, F.; Talanta 1996, 43, 2107.

67. Ferreira, M. M. C.; Antunes, A. M.; Melgo, M. S.; Volpe, P .L. O.; Quim. Nova 1999, 22, 724.

68. Dinc, E.; Baleanu, D.; Farmaco 2002, 57, 33.

69. Dinc, E.; Serin, C.; Tugcu-Demiroz, F.; Doganay, T.; Int. J. Pharm. 2003, $250,339$.

70. Moreira, A. B.; Dias, I .L. T.; Neto, G. O.; Zagatto, E. A. G.; Ferreira, M. M. C.; Kubota, L. T.; Talanta 2005, 67, 65.

71. Bouhsain, Z.; Garrigues, S.; de la Guardia, M.; Analyst 1997, 122, 441.

72. Ohnsmann, J.; Quintas, G.; Garrigues, S.; de la Guardia, M.; Anal. Bional. Chem. 2002, 374, 561.

73. Paradkar, M. M.; Irudayaraj, J.; J. Food Sci. 2002, 67, 2507.

74. Briandet, R.; Kemsley, E. K.; Wilson, R. H.; J. Agric. Food Chem. 1996, 44, 170.

75. Morgano, M. A.; Camargo, C.; Pagel, A. P.; Ferrão, M. F.; Bragagnolo, N.; Ferreira, M. M. C.; II Simpósio de Pesquisa dos Cafés do Brasil, Brasília, Brasil, 2001.

76. Sontag, G.; Kral, K.; Mikrochim. Acta 1979, 229.

77. Kral, K.; Dissertation Abstracts International, C., 1982, 43, 564.

78. Lau, O. W.; Luk, S. F.; Cheung, Y. M.; Analyst 1989, 114, 1047.

79. JyhMyng, Z.; YuanShih, T.; Ying, S.; Analyst 1998, 123, 1145.

80. Moses, P. R.; Wier, P.; Murray, R. W.; Anal. Chem. 1975, 47, 1882.

81. Ly, S. Y.; Jung, Y. S.; Kim, M. H.; Han, I. K.; Jung, W. W.; Kim, H. S.; Microchim. Acta 2004, 146, 207.

82. Safavi, A.; Maleki, N.; Shams, E.; Shahbaazi, H. R.; Electroanalysis, 2002, $14,929$.

83. Prado, C.; Wilkins, S. J.; Marten, F.; Compton, R. G.; Electroanalysis 2002, 14, 262.

84. Khodari, M.; Electroanalysis 1998, 10, 1061

85. Desimoni, E.; Brunetti, B.; Bacchella, R.; Electroanalysis 2002, 14, 459.

86. Pereira, A. C.; Santos, A. S.; Kubota, L. T.; Quim. Nova 2002, 25, 1012.

87. Pizzariello, A.; Svorc, J.; Stred'ansky, M.; Miertus, S.; J. Sci. Food Agric. 1999, 79, 1136. 